\title{
Refinement of Spatial Receptive Fields in the Developing Mouse Lateral Geniculate Nucleus Is Coordinated with Excitatory and Inhibitory Remodeling
}

\author{
Wayne W. Tschetter, ${ }^{1 \star}$ Gubbi Govindaiah, ${ }^{2 *}$ Ian M. Etherington, ${ }^{1}$ William Guido, ${ }^{2} \#$ and $\odot$ Cristopher M. Niell ${ }^{1}$ \\ ${ }^{1}$ Institute of Neuroscience and Department of Biology, University of Oregon, Eugene, Oregon 97403 and ${ }^{2}$ Department of Anatomical Sciences and \\ Neurobiology, University of Louisville School of Medicine, Louisville, Kentucky 40292
}

Receptive field properties of individual visual neurons are dictated by the precise patterns of synaptic connections they receive, including the arrangement of inputs in visual space and features such as polarity (On vs Off). The inputs from the retina to the lateral geniculate nucleus (LGN) in the mouse undergo significant refinement during development. However, it is unknown how this refinement corresponds to the establishment of functional visual response properties. Here we conducted in vivo and in vitro recordings in the mouse LGN, beginning just after natural eye opening, to determine how receptive fields develop as excitatory and feedforward inhibitory retinal afferents refine. Experiments used both male and female subjects. For in vivo assessment of receptive fields, we performed multisite extracellular recordings in awake mice. Spatial receptive fields at eye-opening were $>2$ times larger than in adulthood, and decreased in size over the subsequent week. This topographic refinement was accompanied by other spatial changes, such as a decrease in spot size preference and an increase in surround suppression. Notably, the degree of specificity in terms of $0 \mathrm{n} / \mathrm{Off}$ and sustained/transient responses appeared to be established already at eye opening and did not change. We performed in vitro recordings of the synaptic responses evoked by optic tract stimulation across the same time period. These recordings revealed a pairing of decreased excitatory and increased feedforward inhibitory convergence, providing a potential mechanism to explain the spatial receptive field refinement.

Key words: activity-dependent refinement; receptive field; thalamus

Significance Statement

The development of precise patterns of retinogeniculate connectivity has been a powerful model system for understanding the mechanisms underlying the activity-dependent refinement of sensory systems. Here we link the maturation of spatial receptive field properties in the lateral geniculate nucleus (LGN) to the remodeling of retinal and inhibitory feedforward convergence onto LGN neurons. These findings should thus provide a starting point for testing the cell type-specific plasticity mechanisms that lead to refinement of different excitatory and inhibitory inputs, and for determining the effect of these mechanisms on the establishment of mature receptive fields in the LGN.

\section{Introduction}

Visual receptive fields are shaped during development by the patterns of connections that form between neurons. In the thal-

Received Oct. 2, 2017; revised April 3, 2018; accepted April 10, 2018.

Author contributions: W.W.T., G.G., W.G., and C.M.N. designed research; W.W.T., G.G., and I.M.E. performed research; W.G. and C.M.N. analyzed data; W.W.T., W.G., and C.M.N. wrote the paper.

This work was supported by National Institutes of Health Grants EY12716 (W.G.), EY023337 (C.M.N.), and EY023190 (C.M.N.); and the Knights Templar Eye Foundation (W.W.T.).

The authors declare no competing financial interests.

*W.W.T. and G.G. contributed equally to this work.

$\#$ \#.G. and C.M.N. contributed equally to this work.

Correspondence should be addressed to either of the following: Cristopher Niell, 222 Huestis Building, 1254 University of Oregon, Eugene, OR 97405, E-mail: cniell@uoregon.edu; or William Guido, 511 South Floyd Street,

University of Louisville School of Medicine, Louisville, KY 40292, E-mail: william.guido@louisville.edu. amus, neurons in the lateral geniculate nucleus (LGN) relay sensory information from the retina to the cortex, with spatially localized receptive fields of a given sign (On or Off), which are generated by the highly specific convergence of a few retinal ganglion cell (RGC) inputs. This has been demonstrated by classic experiments in which monosynaptically connected pairs of RGCs and geniculate neurons were simultaneously recorded and found to have an extraordinary degree of similarity between their receptive field sign (On or Off), size, and spatial position (Levick et al., 1972; Mastronarde, 1987; Usrey et al., 1999). This remarkable specificity is known to result from an extensive period of synaptic 
pruning. However, it is not clear what the functional changes are that accompany this pruning. How is refinement at the synaptic level reflected in the receptive field properties of individual neurons?

The mouse model offers an opportunity to study this question. Since the pioneering work of Chen and Regehr (2000), several studies have shown that excitatory retinal afferents in the LGN undergo extensive remodeling during the first few weeks of life, as the number of retinal inputs onto a single LGN neuron is substantially reduced (Guido, 2008; Hong and Chen, 2011). During this time, feedforward inhibitory circuits emerge in the LGN, where retinal axon collaterals branch to make excitatory connections onto GABAergic intrinsic interneurons, which in turn form inhibitory connections with dLGN relay neurons (Bickford et al., 2010).

In this study, we investigated the refinement of both excitatory and feedforward inhibitory inputs onto dLGN relay cells to determine whether there is coordination with receptive field development. After measuring receptive fields using the spiketriggered average estimate of spatial structure, we discovered significant refinement during the first week after eye opening. This included a significant decrease in receptive field size and stimulus size preference. We were also able to determine whether refinement occurs by cell type (On/Off, transient/sustained) or is topographic. To disambiguate the effects of refinement of retinal inputs from changes in retinal receptive fields during development, we mapped RGC receptive fields by recording from axons in the optic nerve in vivo. Last, to further understand the underlying circuitry that accompanies these changes, we recorded excitatory and inhibitory synaptic responses in vitro by applying electrical stimulation to the optic tract in an acute thalamic slice preparation that preserves retinal afferents and intrinsic inhibitory circuitry within the LGN. The in vitro measurements showing a pairing of decreased excitatory convergence with increased inhibitory convergence provide a potential mechanism that shapes adult-like receptive field structures in LGN neurons.

\section{Materials and Methods}

Animal use. For in vivo experiments, mice were maintained in the animal facility at the University of Oregon and used in accordance with protocols approved by the University of Oregon Institutional Animal Care and Use Committees (IACUCs). For in vitro experiments, mice were maintained in a colony in the animal facility at the University of Louisville, and all procedures were conducted in accordance with the University of Louisville IACUC. Experiments were performed on male and female C57BL/6 mice that ranged in age from postnatal day (P) 14 to P60.

Experimental design and statistical analysis. In vivo recordings from LGN neurons were performed from 53 mice, mixed male and female (P14-P16: $N=7$ mice, $n=102$ units; P17-P21: $N=22$ mice, $n=298$ units; P22-P24: $N=7$ mice, $n=115$ units; adult P45-P60: $N=17$ mice, $n=228$ units). Successful in vivo recordings from optic nerve units were performed from 30 mice, mixed male and female (P16-P20: $N=2$ mice, $n=2$ units; P21-P24: $N=3$ mice, $n=4$ units; P25-P30: $N=4$ mice, $n=$ 7 units; adult P45-P60: $N=21$ mice, $n=32$ units). Optic nerve recordings from young animals are greatly under-represented due to the considerable challenge in surgery to expose the optic nerve and the subsequent isolation of units; we were not successful in recording from pups younger than P16. Following spike sorting and data analysis, computed response parameters were pooled into discrete age bins delineated above. Average values for each age bin are presented at median, with error bars representing SE of the median calculated by bootstrap. Statistical significance was determined by Kruskal-Wallis test across ages, with Dunn's correction for multiple comparisons.

In vitro recordings were conducted on 153 neurons from 31 mice (P14: $n=10$ mice, 52 cells; P21: $n=11$ mice, 46 cells; P30: $n=7$ mice, 39 cells;
P60: $n=3$ mice, 16 cells). Statistical significance was determined by Kruskal-Wallis test across ages, with Dunn's correction for multiple comparisons.

Extracellular multisite electrophysiology. Recordings were performed generally as described previously (Piscopo et al., 2013). However, recordings were made in awake animals with a head-fixed paradigm similar to that described by Niell and Stryker (2010).

In preparation for recording, two surgeries were performed. The first was to facilitate head fixation during recording. Custom stainless-steel head-plate implants were cemented to the skull as described previously (Niell and Stryker, 2010). Briefly, animals were anesthetized with isoflurane in oxygen (5\% induction, $1.5 \%$ maintenance) and maintained at $37^{\circ} \mathrm{C}$. The scalp and fascia from bregma to lambda were removed and the skull was cleaned and polished before applying a thin layer of cyanoacrylate (VetBond, WPI). With bregma and lambda exposed, coordinates were marked on the skull to outline the site of the craniotomy. The head plate was then mounted with dental acrylic (Ortho JET, Lang Dental Manufacturing) and the well filled with silicone elastomer (Kwik-Sil, WPI) to protect the skull before recordings.

After 2-3 d of recovery from the head-plate surgery, a second surgery was performed on the morning of recording to make the craniotomy. The animals were anesthetized as described above. The silicone elastomer was removed to expose the skull. A small craniotomy ( $\sim 2 \mathrm{~mm}$ ) was made over the demarcated site, which was centered over the LGN at $2.5 \mathrm{~mm}$ posterior to bregma and $2 \mathrm{~mm}$ lateral from midline. The exposed cortical surface was covered with $1.5 \%$ agarose to prevent drying and then capped with silicone elastomer. The animal recovered for $2-3 \mathrm{~h}$ before recording.

After recovery, the animal was placed in the head-plate holder comfortably positioned on top of a spherical treadmill described previously by Niell and Stryker (2010) and initially developed by Dombeck et al. (2007). Once animals were habituated to the apparatus, the protective agarose and silicone plug were removed. A ground wire was then positioned in the head-plate well and covered with a fresh layer of agarose. We used a custom 64-channel electrode (A2X32-5 mm-25-200-177-A64, Neuronexus Technologies) arranged in a two-shank, linear configuration, with each shank containing 32 channels spaced at $25 \mu \mathrm{M}$. Each shank was coated with a small amount of lipophilic vital dye $\mathrm{DiO}$ (Invitrogen) before being inserted into the brain vertically using a microdrive (Siskiyou Designs). LGN could be identified at $\sim 2500-3000 \mu \mathrm{M}$ by rapid firing in response to focal stimuli at a specific location within the visual field. After insertion, additional agarose was added to stabilize the electrode and the preparation was allowed to settle for $30 \mathrm{~min}$. Typically only one penetration was made per animal to avoid excessive bleeding and damage to the LGN and overlying tissue. Only units stably isolated over the entire recording duration were used in subsequent analysis.

In vivo recording of RGCs. The optic nerve recording method was adapted from a previously published protocol (Sagdullaev and McCall, 2005). In preparation for surgery and recording, animals were anesthetized and the skull was exposed as described above. To maintain head fixation for stable recording, a modified head plate was mounted near the back of the skull using the materials and procedures also described above. After the mouse was mounted on the holding platform, a craniotomy of $\sim 2 \mathrm{~mm}$ in diameter was performed anterior to the bregma suture and the overlying cortical tissue was removed to expose the optic nerve. At this point the mouse was transferred in the holding platform to the recording setup where the platform was mounted to the work surface. Action potentials were recorded extracellularly using microelectrodes etched from tungsten rods (A-M Systems), coated with varnish and adjusted to a final impedance of 1-3 $M \Omega$. Once the electrode was lowered onto the nerve, single units were isolated using audio feedback of spiking activity during small mechanical adjustments of the electrode position. Due to limitations in stability of axon isolation, we only presented white noise stimuli in these recordings.

Data acquisition. Data acquisition for in vivo recording was performed as described previously (Niell and Stryker, 2008). Signals were acquired using a System 3 workstation (Tucker-Davis Technologies) and analyzed with custom routines written in Matlab (Mathworks). To obtain singleunit activity, the extracellular signal was filtered from $0.7-7 \mathrm{kHz}$ and sampled at $25 \mathrm{kHz}$. Spiking events were detected on-line by voltage 
threshold crossing and a $1 \mathrm{~ms}$ waveform sample was acquired around the time of threshold crossing. For silicon probe recordings, the waveform was sampled simultaneously on groups of four neighboring sites. Singleunit clustering and spike waveform analysis were performed as described previously (Niell and Stryker, 2008) with a combination of custom software in Matlab and KlustaKwik (Harris et al., 2000). The quality of isolation was based on quantitative measures of cluster separation and evidence of a clear refractory period. Units were also checked for stability in terms of amplitude and waveform over the entire recording session to ensure they had not drifted. Units found by histology to be above or below the LGN, due to the length of the electrode, were excluded from subsequent analysis.

Visual stimuli and data analysis. Visual stimuli were presented as described previously (Niell and Stryker, 2008; Piscopo et al., 2013). Briefly, stimuli were generated using the Psychophysics Toolbox extensions (Brainard, 1997; Pelli, 1997) and displayed using gamma correction on an LCD monitor (Planar SA2311W, $30 \times 50 \mathrm{~cm}, 60 \mathrm{~Hz}$ refresh rate) placed $25 \mathrm{~cm}$ from the mouse, subtending $\sim 60-75^{\circ}$ of visual space. The monitor was either centered directly in front of the mouse or offset to $45^{\circ}$ and raised or lowered to accommodate receptive field locations. We used a range of visual stimuli previously (Piscopo et al., 2013) shown to drive canonical and noncanonical responses of dLGN neurons.

Drifting sinusoidal gratings (Piscopo et al., 2013) were presented at eight evenly spaced directions of motion, at spatial frequencies of 0.01 , $0.02,0.04,0.08,0.14,0.32$ cycles $/{ }^{\circ}$, and at 2 and $8 \mathrm{~Hz}$ temporal frequency. Stimuli were randomly interleaved and included a gray blank condition (mean luminance) to estimate the spontaneous firing rate.

Sparse flashing noise (Piscopo et al., 2013) consisted of On (full luminance) and Off (minimum luminance) circular spots on a gray background. Spots were $2,4,8,16$, and $32^{\circ}$ in diameter and presented at a density such that on average $15 \%$ of the area on the screen was covered on any given frame and that each size made up an equal fraction of the area on the screen. This ensured even coverage at each point in space by every size. In addition, 20 frames each of full-screen On and Off were randomly interleaved. Each movie frame was presented for $250 \mathrm{~ms}$ followed by immediate transition to the next frame. The stimulus was presented for $20 \mathrm{~min}$.

Contrast modulated noise movies (Niell and Stryker, 2008) were created by generating a random spatiotemporal frequency spectrum in the Fourier domain with defined spectral characteristics. To drive as many simultaneously recorded units as possible, we used a spatial frequency spectrum that dropped off as $A(f) \sim 1 /\left(f+f_{\mathrm{c}}\right)$, with $f_{\mathrm{c}}=0.05$ cycles $/^{\circ}$, and a sharp cutoff at $0.16 \mathrm{cycles} /{ }^{\circ}$, to approximately match the stimulus energy to the distribution of spatial frequency preferences. The temporal frequency spectrum was flat with a sharp low-pass cutoff at $10 \mathrm{~Hz}$. This $3 \mathrm{D}\left(\omega_{x}, \omega_{y}, \omega_{t}\right)$ spectrum was then inverted to generate a spatiotemporal movie. To provide contrast modulation, this movie was multiplied by a sinusoidally varying contrast with a $10 \mathrm{~s}$ period. Each movie was $5 \mathrm{~min}$ long and was repeated $\sim 4$ times for 20 min total presentation.

Data analysis for visual response properties. To analyze the response to contrast-modulated white noise movies, we binned the number of spikes in response to each frame of the movie. The spatiotemporal spiketriggered average (STA) of contrast-modulated movie responses was computed by the mean of the frames at a range of temporal offsets before each spike. Because we used a $1 / f$ power spectrum for the stimulus set, the raw STA is broadened by the correlations in the stimulus set. However, because the stimulus is Gaussian and therefore only contains secondorder correlations, we were able to correct the STA exactly by normalizing its Fourier transform by the power spectrum of the stimulus set (Sharpee et al., 2004). We used singular value decomposition to separate the joint spatiotemporal receptive field into pairs of spatial and temporal components (Wolfe and Palmer, 1998). For all units with an evident response in the joint STA, this gave a spatial component with a clearly localized response, which was used as the spatial STA. Units that did not have a spatial STA component with amplitude significantly above the noise background were left unclassified for spatial receptive field analysis. The spatial STA was then fit to a 2D Gaussian to determine receptive field center and amplitude. This fit does not take into account opposing surrounds, which would require a fit to a difference of two Gaussians and therefore is less robust, but this was clearly sufficient for determining receptive field location and polarity, as well as a measure of receptive field center size.

To analyze sparse noise movies, we computed spiked-triggered averages for On and Off spots separately (to avoid averaging out On/Off responses in nonlinear units) and determined the receptive field location as the point with the largest absolute magnitude response across the two STAs. We computed peristimulus time histograms locked to the onset of each flashed spot that coincided with this location. Histograms were separated out based on polarity and size of the spot. The mean response during spot presentation $(250 \mathrm{~ms})$ was used to determine response amplitude as a function of polarity and size.

We computed a measure of On/Off segregation at each location as $\left(R_{\mathrm{ON}}-R_{\mathrm{OFF}}\right) /\left(R_{\mathrm{ON}}+R_{\mathrm{OFF}}\right)$ where $R_{\mathrm{ON}}$ and $R_{\mathrm{OFF}}$ are the mean firing rates at the preferred size for On and Off stimulus respectively. This measure will be +1 for a neuron that responds only to On, -1 for a neuron that responds only to Off, and 0 for a neuron that responds to both equally. On/Off uniformity was calculated as the absolute value of the average of this index across the receptive field, so that a neuron that responds only to On or Off at all points will have a value of 1 , whereas a neuron that responds to both On and Off either at the same location or at different locations in the receptive field will have a value of 0 .

A measure of sustained response was generated as the ratio of the mean response during spot presentation to the peak response, for the preferred size and polarity. A unit that responds equally throughout the presentation will have a value of 1 , whereas a unit that only responds briefly will have a value close to 0 . We computed the uniformity as $1-\mathrm{SD}$ of this measure across all locations in the receptive field, so that units with consistent sustain/transient index (low SD) will have an index of 1 .

Responses to grating stimuli were analyzed by computing both the $F 0$ response (mean firing rate) and $F 1$ response (modulation of firing rate at temporal frequency of the gratings). The response that was greater was taken as the measure of the cells' response amplitude and was used to compute subsequent properties. Spatial frequency tuning was computed by averaging across the eight orientations that were presented. Orientation and direction selectivity were determined for the preferred spatial frequency, and measured using the circular variance as an index of global selectivity, as described in Piscopo et al. (2013).

Thalamic slice preparation and in vitro recording. To examine the synaptic responses evoked by optic tract stimulation, we used an acute thalamic slice preparation that preserves retinal and intrinsic inhibitory connections in the dLGN (Chen and Regehr, 2000; Dilger et al., 2011, 2015; Seabrook et al., 2013). Mice were deeply anesthetized with isoflurane inhalation and decapitated. The brain was removed from the skull and immersed into an oxygenated $\left(95 \% \mathrm{O}_{2} / 5 \% \mathrm{CO}_{2}\right) 4^{\circ} \mathrm{C}$ sucrose solution (in mM: $2.5 \mathrm{KCl}, 26 \mathrm{NaHCO}_{3}, 2.5 \mathrm{KCl}, 1.25 \mathrm{NaH}_{2} \mathrm{PO}_{4}, 10 \mathrm{MgCl}_{2}, 2$ $\mathrm{CaCl}_{2}, 234$ sucrose, and 11 glucose). The two hemispheres were separated by cutting along the midline at an angle of $10^{\circ}$. The medial aspect of one hemisphere was glued onto a tilted $\left(20^{\circ}\right)$ stage of a vibratome (Leica VT1000S) and 250-300- $\mu \mathrm{m}$-thick sections were cut in the parasagittal plane. Before recording, slices were incubated in a holding chamber containing an oxygenated artificial CSF (ACSF) solution (in mM: $126 \mathrm{NaCl}$, $26 \mathrm{NaHCO}_{3}, 2.5 \mathrm{KCl}, 1.25 \mathrm{NaH}_{2} \mathrm{PO}_{4}, 2 \mathrm{MgCl}_{2}, 2 \mathrm{CaCl}_{2}$, and 10 glucose) for $30 \mathrm{~min}$ at $32^{\circ} \mathrm{C}$ and then brought to room temperature. Individual slices containing the dLGN and a large segment of the optic tract were transferred to a recording chamber maintained at $32^{\circ} \mathrm{C}$ and then perfused continuously at a rate of $2.5 \mathrm{ml} / \mathrm{min}$ with oxygenated ACSF.

In vitro recordings were performed in a whole-cell configuration with the aid of a fixed-stage microscope (Olympus BX51WI) equipped with differential interference contrast optics and a water-immersion objective to view individual neurons within the slice. Patch electrodes were pulled vertically (Narishige) in two stages from borosilicate glass and filled with an internal recording solution (in mM: $117 \mathrm{~K}$-gluconate, $13.0 \mathrm{KCl}, 1$ $\mathrm{MgCl}_{2}, 0.07 \mathrm{CaCl}_{2}, 0.1$ EGTA, 10 HEPES, $2 \mathrm{Na}$-ATP, and $0.4 \mathrm{Na}$-GTP; or 117.0 Cs-gluconate, 13.0 CsCl, 1.0 MgCl2, 0.07 CaCl2, 0.1 EGTA, 10.0 HEPES, 2.0 Na2-ATP, 0.4 Na-GTP, pH 7.3, 290 Osmol/L).

Whole-cell recordings were obtained using a Multiclamp 700B amplifier (Molecular Devices). Neuronal activity was filtered at $1-2 \mathrm{kHz}$, digitized at $10 \mathrm{kHz}$ (Digidata 1440A, Molecular Devices), stored on a 


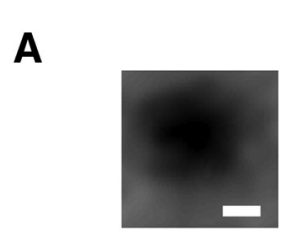

B

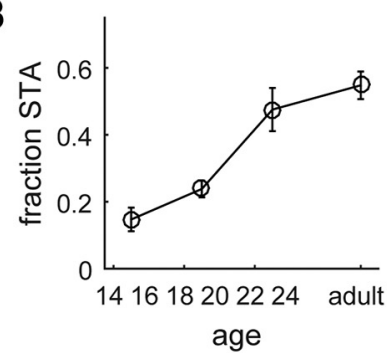

P14-16

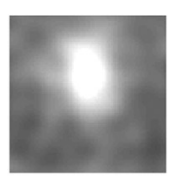

C
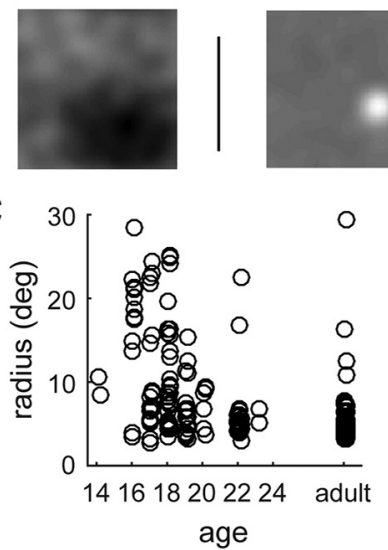

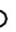

Adult

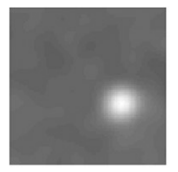

D

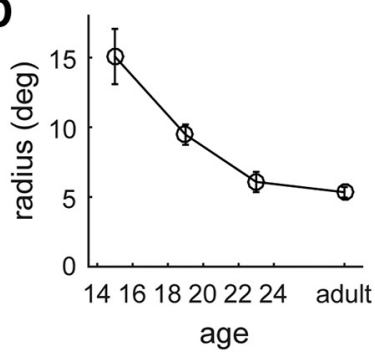

Figure 1. Spatial refinement of LGN receptive fields over the course of development. $\boldsymbol{A}$, Examples of spike-triggered average receptive fields at P16 and in adulthood. Scale bar, $10^{\circ}$. $\boldsymbol{B}$, Fraction of LGN neurons with a clearly mapped spike-triggered average receptive field across the course of development. $\boldsymbol{C}$, Receptive field radius, from a Gaussian fit to the spatial STA, over the course of development. Circles represent individual single units. D, Average receptive field radius across the course of development.

computer, and analyzed using pCLAMP 10 (Molecular Devices). Pipette capacitance, series resistance, and whole-cell capacitance were continuously monitored and compensated electronically during the recording.

To evoke synaptic activity in dLGN cells, single square-wave pulses $(0.3 \mathrm{~ms}, 1-1000 \mathrm{uA})$ were delivered through a pair of thin-gauge tungsten wires $(0.5 \mathrm{M} \Omega)$ positioned in the optic tract. Estimates of retinal convergence were accomplished by generating EPSC amplitude by stimulusintensity plots (Dilger et al., 2011, 2015; Seabrook et al., 2013). These were constructed by first determining the minimum stimulus intensity needed to evoke a postsynaptic response. Once the single-fiber response was determined, current intensity was increased in small increments $(0.5-1.0 \mathrm{uA})$ until a response of maximal amplitude was consistently reached. For each stimulus intensity, an average amplitude based on five responses was generated. A change in amplitude equal to or exceeded a value that corresponded to the amplitude of the single-fiber response was used to distinguish one input from another (Dilger et al., 2011, 2015; Seabrook et al., 2013). We also computed a fiber fraction as an additional estimate of convergence, which is based on the ratio of single-fiber minimal response divided by the maximal response (Hooks and Chen, 2006; Thompson et al., 2017). EPSCs were evoked at a holding potential of -70 $\mathrm{mV}$ in the presence of the $\mathrm{GABA}_{\mathrm{A}}$ receptor antagonist 4-[6-imino-3-(4methoxyphenyl) pyridazin-1-yl] butanoic acid hydrobromide (SR95531; $10 \mu \mathrm{M}$ ). We used the same optic tract stimulation protocol to examine the degree of feedforward inhibitory input onto dLGN relay cells that arises from their connections with intrinsic interneurons (Bickford et al., 2010). To isolate IPSCs, we used cesium-based electrodes and recorded synaptic responses at a holding potential of $0 \mathrm{mV}$ (Crandall and Cox, 2013).

During some of the recordings, a biocytin solution $(0.1-0.2 \%)$ was included in the patch pipette. Neurons were filled by passing alternating positive and negative current pulses $( \pm 0.5 \mathrm{nA}, 200 \mathrm{~ms})$ through the recording electrode. After recording, slices were fixed and biocytin-filled neuron immunocytochemistry and reconstruction were done using methods described previously (Krahe et al., 2011).

\section{Results}

To determine whether there is coordinated refinement between receptive fields and retinogeniculate circuits during development, we used 64-channel silicon electrodes to record the responses of LGN neurons in awake mice, spanning the first week after eye opening and then in adulthood. Recordings were made from a total of 743 LGN neurons in 53 mice (P14-P16: $N=7$ mice, $n=102$ units; P17-P21: $N=22$ mice, $n=298$ units; P22-P24: $N=7$ mice, $n=115$ units; adult P45-P60: $N=17$ mice, $n=228$ units). To test the hypothesis that receptive fields are shaped by refinement in retinogeniculate convergence, we made in vitro whole-cell recordings of synaptic responses in 153 LGN neurons from 31 mice (P14: $n=10$ mice, 52 cells; P21: $n=$ 11 mice, 46 cells; P30: $n=7$ mice, 39 cells; P60: $n=3$ mice, 16 cells). This allowed us to estimate the number of excitatory and feedforward inhibitory inputs in the LGN at the same developmental time points that we used when we measured receptive fields. To rule out the possibility that the developmental effects in LGN receptive fields are a reflection of retinal processing or optics of the eye in young mice, we recorded from RGC axons in the optic nerve in vivo.

\section{Development of receptive field spatial structure}

To map spatial receptive fields in the mouse LGN, we recorded extracellular responses of LGN neurons to a $1 / f$ band-limited noise stimulus (Piscopo et al., 2013) and computed the spatial STA of the stimulus response. Figure $1 A$ shows representative examples of mapped receptive fields at P14, P16, and adulthood. During the first 4-5 d after eye opening, receptive fields were typically very large and varied in shape ranging from circularly symmetric to elongated. Often multiple peaks within the receptive field could be distinguished around the time of eye opening, as previously reported in developing ferret LGNs (Tavazoie and Reid, 2000). By the end of the first week after eye opening, most exhibited an adult-like circular structure (Fig. 1A, Adult). Often, the center-surround spatial organization could be resolved in the STA of adult receptive fields.

We quantified receptive field size by fitting each receptive field map to a $2 D$ Gaussian. Figure $1 B$ shows that the fraction of cells that produced a receptive field map that could be fit to a Gaussian increased over the course of development from $\sim 15 \%$ at eye opening to $55 \%$ in adulthood (P14-P16: $0.14 \pm 0.04$; P17P21: $0.24 \pm 0.02$; P22-P24: $0.48 \pm 0.06$; adult: $0.55 \pm 0.04$; Kruskal-Wallis $\mathrm{H}=64.5, p=6.2 \times 10^{-14}$ ), a fraction approximately the same as that previously published for adult mouse LGNs (Piscopo et al., 2013). Of the population of cells with a spatially defined receptive field (Fig. $1 C$ ), there is a $\sim 3$-fold decrease in receptive field size over the first week after eye opening (Fig. $1 D$; P14-P16: $15.1 \pm 2.0^{\circ}$; P17-P21: $9.5 \pm 0.7^{\circ}$; P22-P24: $6.1 \pm 0.7^{\circ}$; adult: $5.3 \pm 0.4^{\circ}$; Kruskal-Wallis $\mathrm{H}=$ 41.6, $p=5.0 \times 10^{-9}$ ). 
A

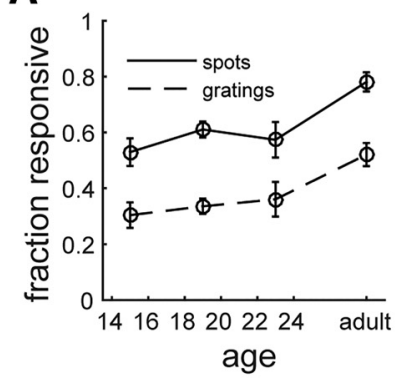

E

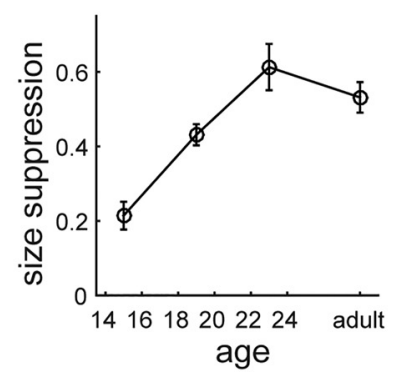

B

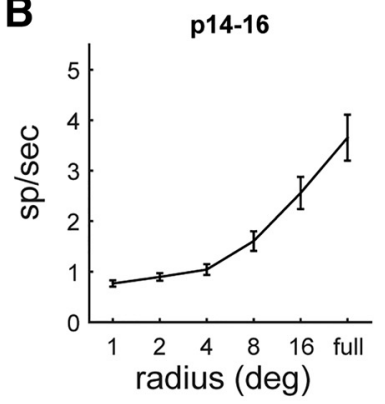

F

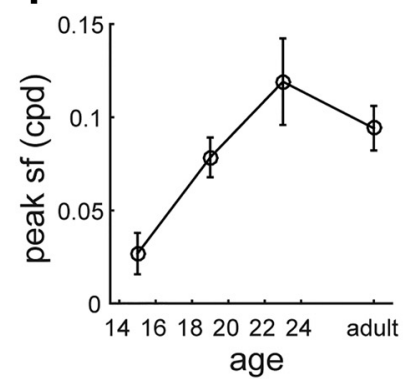

C

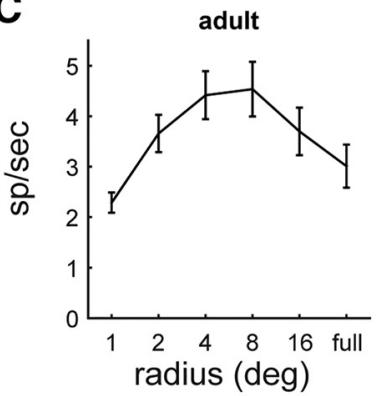

G

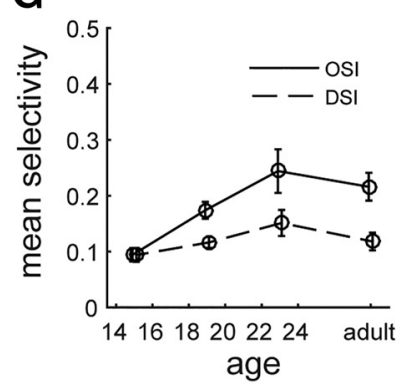

D

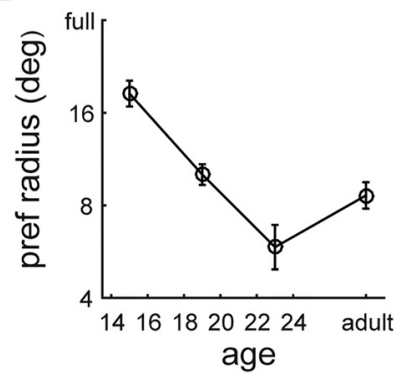

Figure 2. Size selectivity of $L G N$ neurons over the course of development. $\boldsymbol{A}$, Fraction of units responsive (rate, $>2$ spikes/s) to flashing spots and drifting grating stimuli. $\boldsymbol{B}, \boldsymbol{C}$, Average size tuning curve across the population at P14-P16 (B) and in adulthood (C). D, Average preferred spot size over the course of development. $\boldsymbol{E}$, Average size suppression (calculated as fractional decrease in response to full-field flash vs preferred size) over the course of development. $\boldsymbol{F}$, Average peak spatial frequency as measured with full-field drifting gratings. $\boldsymbol{G}$, Average orientation and direction selectivity, based on circular variance, as measured with full-field drifting gratings.

Development of size and spatial frequency tuning properties Since the size of visual receptive fields dictates the spatial scale at which objects can be resolved, we asked whether size and spatial frequency tuning properties would show a concomitant change with age. Using the sparse noise stimulus, which consists of flashing spots of different sizes, we measured size tuning beginning at eye opening. The fraction of units responsive to the flashing spots ( $>2$ spikes/s) increased over development (Fig. 2A), although this was not as large a change as for STA receptive fields (Fig. 1B). Figure $2 B$ shows the size tuning of the population from P14 to P16 and reveals that the largest stimuli, up to a full-field flash, elicit the greatest response (Kruskal-Wallis $\mathrm{H}=89.7, p=7.7 \times$ $\left.10^{-18}\right)$. In adulthood, the peak response is for intermediate size spots, with smaller response to large spots and full-field flash (Fig. $2 C, D$; Kruskal-Wallis $\mathrm{H}=21.1, p=8.0 \times 10^{-4}$ ), resulting in a bandpass tuning curve consistent with center surround receptive fields. This suggests that not only is there a decrease in the size of the receptive fields by $\mathrm{P} 17$, but the organization of receptive fields is also being defined.

To determine whether the magnitude of attenuation to large stimuli increases with age, we measured size suppression by comparing the optimal stimulus response to full-field stimulus response. We found that across the ages tested, size suppression increases (P14-P16: $0.21 \pm 0.04$; P17-P21: $0.43 \pm 0.03$; P22P24: $0.61 \pm 0.06$; adult: $0.53 \pm 0.04$; Kruskal-Wallis $\mathrm{H}=36.9$, $p=4.8 \times 10^{-8}$ ) over the first week after eye opening and peaks from P20 to P22 (Fig. 2E). A similar trend emerged in the preferred spot size (Fig. 2D), where initially spot size preference decreased but then slightly rebounds by adulthood (P14-P16: $18.5 \pm 1.9^{\circ}$; P17-P21: $10.0 \pm 0.8 ;$ P22-P24: $5.9 \pm 1.1$; adult: $8.6 \pm$ 0.9 ; Kruskal-Wallis $\left.\mathrm{H}=38.42, p=2.3 \times 10^{-8}\right)$. It is notable that the magnitude of the decrease in preferred spot size observed from eye opening to P21 is similar in magnitude to the decrease in receptive field size (Fig. 1D).
The combination of refinement in receptive fields and spot size suggests that there would be improvements in the response to fine spatial details. To test this, we measured spatial frequency tuning over the course of development by presenting drifting sinusoidal gratings at multiple orientations and spatial frequencies. The fraction of units responsive to gratings ( $>2$ spikes/s) increased over the course of development (Fig. $2 A$ ), although this was not as large a change as for STA receptive fields. As shown in Figure $2 F$, we found a large increase in preferred spatial frequency, from $\sim 0.02$ cycles $/{ }^{\circ}$ at $\mathrm{P} 14-\mathrm{P} 16$ to 0.12 cycles $^{\circ}{ }^{\circ}$ by 1 week later (P14-P16: $0.02 \pm$ 0.01 cycles $/{ }^{\circ} ; \mathrm{P} 17-\mathrm{P} 21: 0.08 \pm 0.01$ cycles $/{ }^{\circ} ; \mathrm{P} 22-\mathrm{P} 24: 0.12 \pm$ $0.02 \mathrm{cycles}^{\circ}{ }^{\circ}$; adult: $0.09 \pm 0.01 \mathrm{cycles}^{\circ}{ }^{\circ}$; Kruskal-Wallis $\mathrm{H}=$ 28.38, $\left.p=3.0 \times 10^{-6}\right)$, consistent with the refinements seen in receptive fields and size selectivity.

Based on the responses to drifting gratings, we also determined the orientation and direction selectivity across development. Consistent with previous findings (Marshel et al., 2012; Piscopo et al., 2013, Zhao et al., 2013), we found a moderate level of orientation and direction selectivity (Fig. $2 G$ ), with orientation selectivity more prevalent. The mean direction selectivity in the population did not change significantly over the course of development (P14-P16: $0.09 \pm 0.01$; P17-P21: $0.12 \pm 0.01$; P22-P24: $0.15 \pm 0.02$; adult: $0.12 \pm 0.02$; Kruskal-Wallis $\mathrm{H}=5.16, p=$ $0.16)$. However, the mean orientation selectivity approximately doubled (P14-P16: 0.09 \pm 0.01; P17-P21: $0.15 \pm 0.02$; P22-P24: $0.24 \pm 0.04$; adult: $0.21 \pm 0.02$; Kruskal-Wallis $\mathrm{H}=17.11, p=$ $\left.7.0 \times 10^{-3}\right)$.

Several measures of response refinement appear to show a slight regression from P22 to adulthood (Fig. $2 C-F$ ). While this was consistent across multiple measures, it was not statistically significant and we therefore do not draw any conclusions from this change. 
A

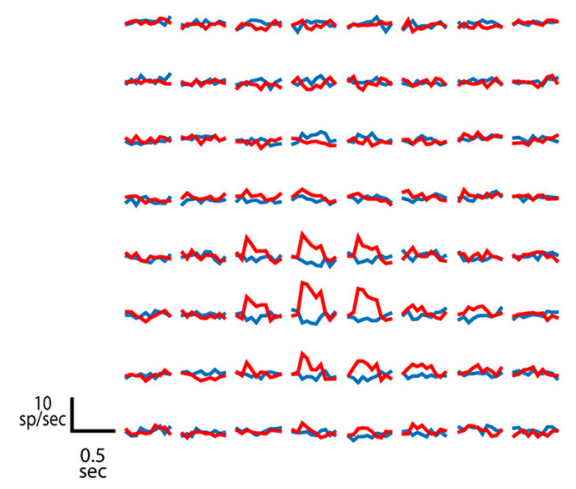

B ON ${ }_{-1}^{1}$
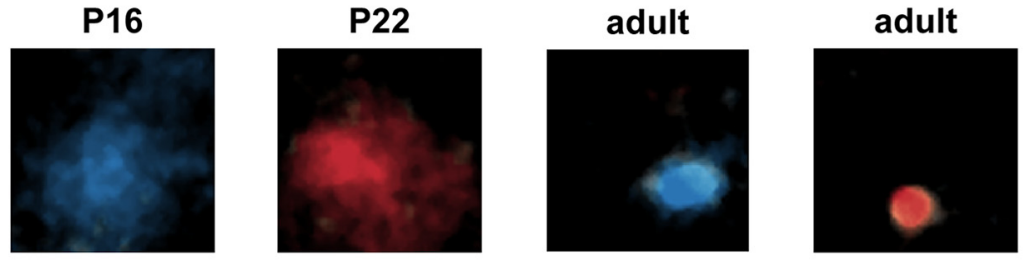

D

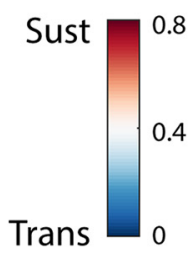

P16

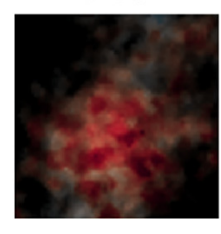

P22

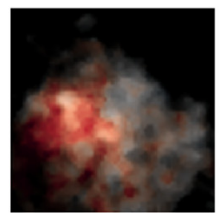

adult

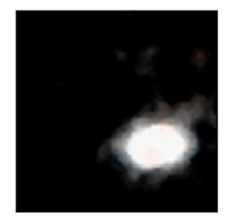

adult

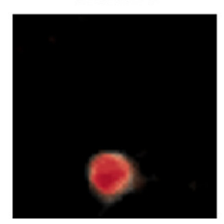

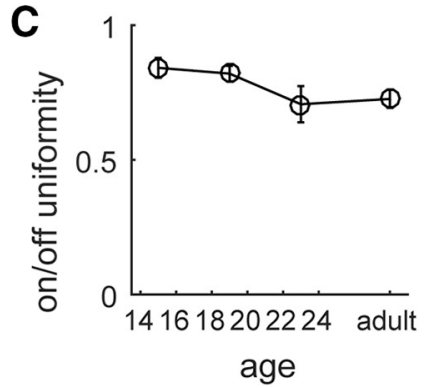

E

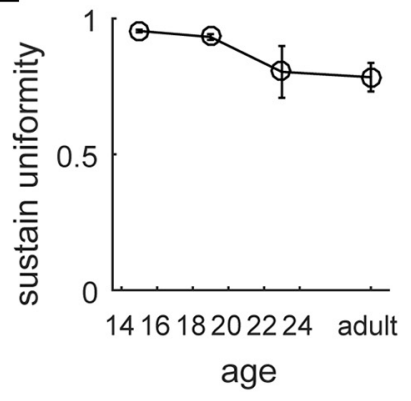

Figure 3. Tuning properties are homogeneous across the spatial receptive field throughout development. $A$, Time course of response to light and dark spots mapped across the visual field, for the On sustained unit shown in rightmost panels of $\boldsymbol{B}$ and $\boldsymbol{D}$. Plots are from individual pixel locations at $4^{\circ}$ spacing. $\boldsymbol{B}$, Examples of spatial distribution of $0 \mathrm{n} / \mathrm{Off}$ responses at $\mathrm{P} 16, \mathrm{P} 22$, and adulthood. Color represents the $0 \mathrm{n} / \mathrm{Off}$ index at each point $(-1$ for $0 \mathrm{ff},+1$ for $0 \mathrm{n})$, and brightness represents amplitude of STA receptive field. Scale bar, $10^{\circ}$. C, Average uniformity of On/Off tuning over the course of development. $\boldsymbol{D}$, Examples of spatial distribution of sustained/transient tuning at P16, P22, and adulthood. Color represents the sustain index at each point, and brightness represents amplitude of STA receptive field. Scale bar, $10^{\circ}$. E, Average uniformity of sustained/transient tuning over the course of development.

\section{Cell-type versus topographic refinement}

In addition to their spatial location and extent, LGN receptive fields can be defined by the polarity of their response to light (On and Off) and the temporal dynamics of their response (sustained and transient). These properties also correspond to distinct classes of RGCs. We asked whether refinement in the retinogeniculate circuit after eye opening also represents an elimination of inputs that are of different functional types (e.g., On vs Off, sustained vs transient) or is primarily topographic in nature as demonstrated by the decrease in receptive field size described above. If refinement does represent pruning of functional classes, then we would expect to see receptive fields that have mixed On and Off, or mixed sustained and transient, responses early after eye opening.

To address this, we analyzed the responses to the sparse noise stimulus consisting of light and dark circular spots on a gray background, which was used to calculate size selectivity above. We separately characterized the temporal response to the light (On) and dark (Off) spots presented at each location on the screen (Fig. 3A). This enabled us to determine whether an LGN neuron received both $\mathrm{On}$ and Off responses across its receptive field, and whether the temporal dynamics (sustained vs transient) varied across the receptive field, either of which would be indicative of input from multiple RGC types.

Figure $3 A$ shows the responses across the visual field for an On sustained unit. At each location where there was a significant response, the cell responded to the light stimulus with activity that was sustained through the $0.5 \mathrm{~s}$ presentation. Based on the pattern of activation at each location, we mapped an On/Off index across the visual field, representing the relative strength of response to On versus Off, shown for four example cells in Figure $3 B$. For all of these cells, the On/Off index had the same sign across the receptive field, indicating that its response was dominated by inputs of the same polarity. To summarize a cell's uniformity, we took the absolute value of the mean On/Off index across the receptive field; if a cell's response is purely On/Off, this would give a value of 1 , whereas if the cells response is mixed, either at each location or across the receptive field, this will aver- 
A

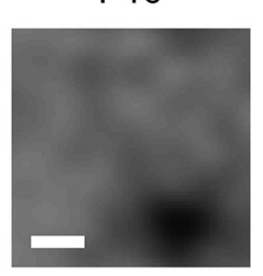

B

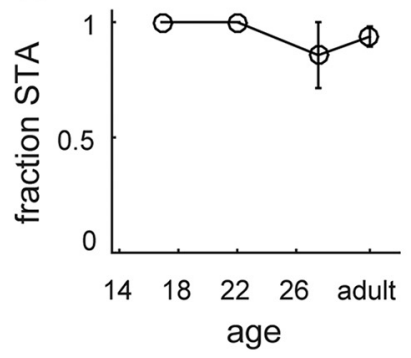

P18

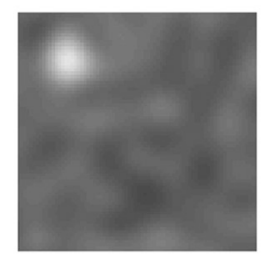

C

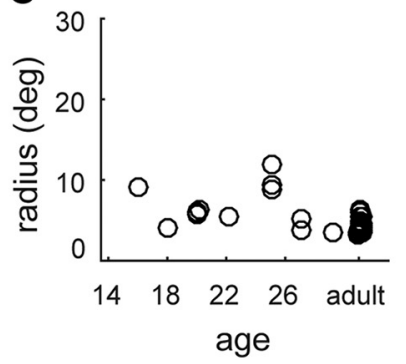

P21

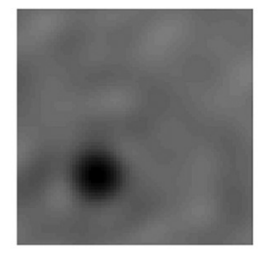

D

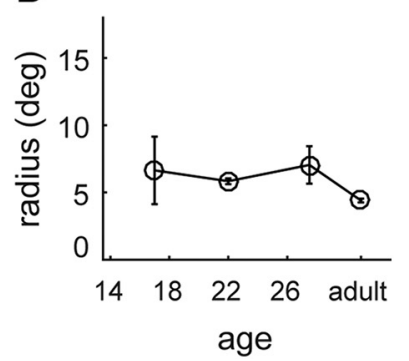

Figure 4. RGC receptive fields do not undergo significant spatial refinement following eye opening. $\boldsymbol{A}$, Example RGC spike triggered average receptive field measured at P16, P18, P21, and adulthood. Scale bar, $10^{\circ}$. B, Fraction of RGC neurons with a clearly mapped spike-triggered average receptive field across the course of development. $\boldsymbol{C}$, Receptive field radius, from STA, over the course of development. Circles represent individual single units. $\boldsymbol{D}$, Average receptive radius across the course of development, showing little change across the period of $L G N$ refinement.

age to 0 . Figure $3 C$ shows a high degree of uniformity even just after eye opening, with little change at later postnatal ages, suggesting that retinogeniculate pruning does not reflect the elimination of inputs from the incorrect polarity (P14-P16: $0.84 \pm$ 0.04; P17-P21: $0.82 \pm 0.03$; P22-P24: $0.71 \pm 0.07$; adult: $0.73 \pm$ 0.03; Kruskal-Wallis $\mathrm{H}=4.55, p=0.2$ ).

We performed a similar analysis for the temporal response, calculating a sustain/transient index analogous to the On/Off index. Figure $3 D$ shows examples of the sustain/transient index across the receptive field for the same units at Figure $3 B$, demonstrating that the temporal dynamics of the response are also consistent across the receptive field. For each cell, we also calculated a temporal uniformity, based on the SD of the sustain/transient index across the receptive field. Figure $3 E$ shows that the uniformity does not improve over the course of retinogeniculate refinement; in fact we observed a small, though significant, decrease in uniformity with age (P14-P16: $0.95 \pm 0.005$; P17-P21: $0.93 \pm$ 0.01; P22-P24: $0.80 \pm 0.10$; adult: $0.78 \pm 0.05$; Kruskal-Wallis $\left.\mathrm{H}=17.3, p=6.0 \times 10^{-4}\right)$. Together, this analysis shows that even at eye opening, although a cell may receive inputs from a large region of visual space, these inputs are dominated by one polarity (On/Off) and one temporal response (sustain/transient). Thus, the type of RGC input that a responsive LGN cell receives appears to be set by eye opening, and subsequent refinement likely reflects the selection of retinotopically appropriate inputs from within this cell type.

\section{RGC receptive fields show little refinement}

From the results above, it remains possible that the change in receptive field size in LGN cells could simply represent a change in the size of RGC receptive fields. Previous studies have shown only a small decrease in RGC receptive field diameter, 10-25\%, as measured with in vitro retinal whole-mount electrophysiology (Cantrell et al., 2010; Koehler et al., 2011), which would not account for the large changes we observe in dLGNs. However, it remains possible that, in vivo, other factors may affect the spatial response of RGCs, such as changes in the optics of the eye. As a control for this possibility, we recorded from RGC axons in the optic tract of anesthetized mice, to measure RGC receptive fields in vivo over the course of development.

Figure $4 A$ shows RGC spike-triggered average receptive fields measured at three different ages (P16, P18, and adulthood). Nearly all units show compact spike-triggered average receptive fields (Fig. 4B), suggesting that most units are dominated by On or Off inputs, although it is important to note that Tian and Copenhagen (2003) observed continued refinement of On/Off segregation over the time period we studied, which is difficult to detect with white noise spike-triggered average. The receptive fields we measured in RGC axons were much smaller than those observed in LGNs at comparable ages. This was true across the population of units that we recorded (Fig. $4 C, D$ ), demonstrating that the size of RGC receptive fields shows only a small change consistent with previous findings (P16-P18: $6.6 \pm 2.5$; P20-P24: $5.8 \pm 0.2$; P25-P30: $7.0 \pm 1.4$; adult: $4.4 \pm 0.2$; Kruskal-Wallis $\mathrm{H}=8.14, p=0.043$ ) during the same period when $\mathrm{LGN}$ receptive fields become smaller by a factor of 3 (Fig. 1D). Thus, we conclude that the decrease in receptive field size in LGNs is likely due to a reduction in the number of RGC inputs rather than a change in the receptive field size of the RGC inputs.

\section{In vitro measurements of retinogeniculate refinement}

To understand the underlying circuitry that accompanies these changes in receptive field properties, we made in vitro whole-cell recordings of dLGN relay neurons in an acute thalamic slice preparation that preserves retinal and intrinsic inhibitory connections onto dLGN relay neurons. Estimates of retinal and inhibitory convergence at different postnatal ages were obtained by examining the changes in amplitude of EPSCs and IPSCs evoked by systematic increases in the intensity of optic tract stimulation. Recordings were restricted to relay neurons, as defined by their electrophysiological properties and, in many cases $(n=88$ of 153), by their dendritic morphology reconstructed from biocytin fills conducted during the recording (Krahe et al., 2011).

Figure $5 A$ shows examples of the EPSCs evoked by optic tract stimulation of dLGN cells at P14, P21, P30, and P60. Responses were evoked at progressively higher levels of stimulus intensity 
A

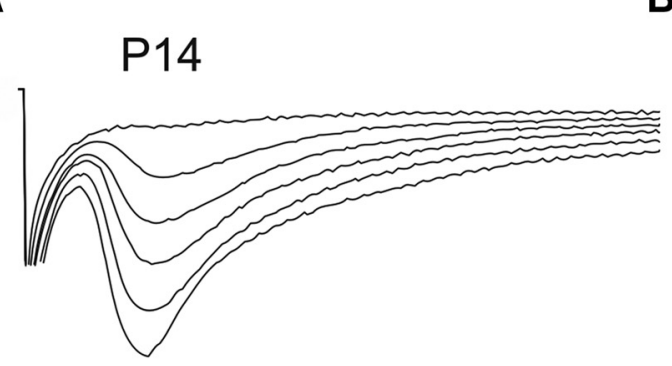

P21
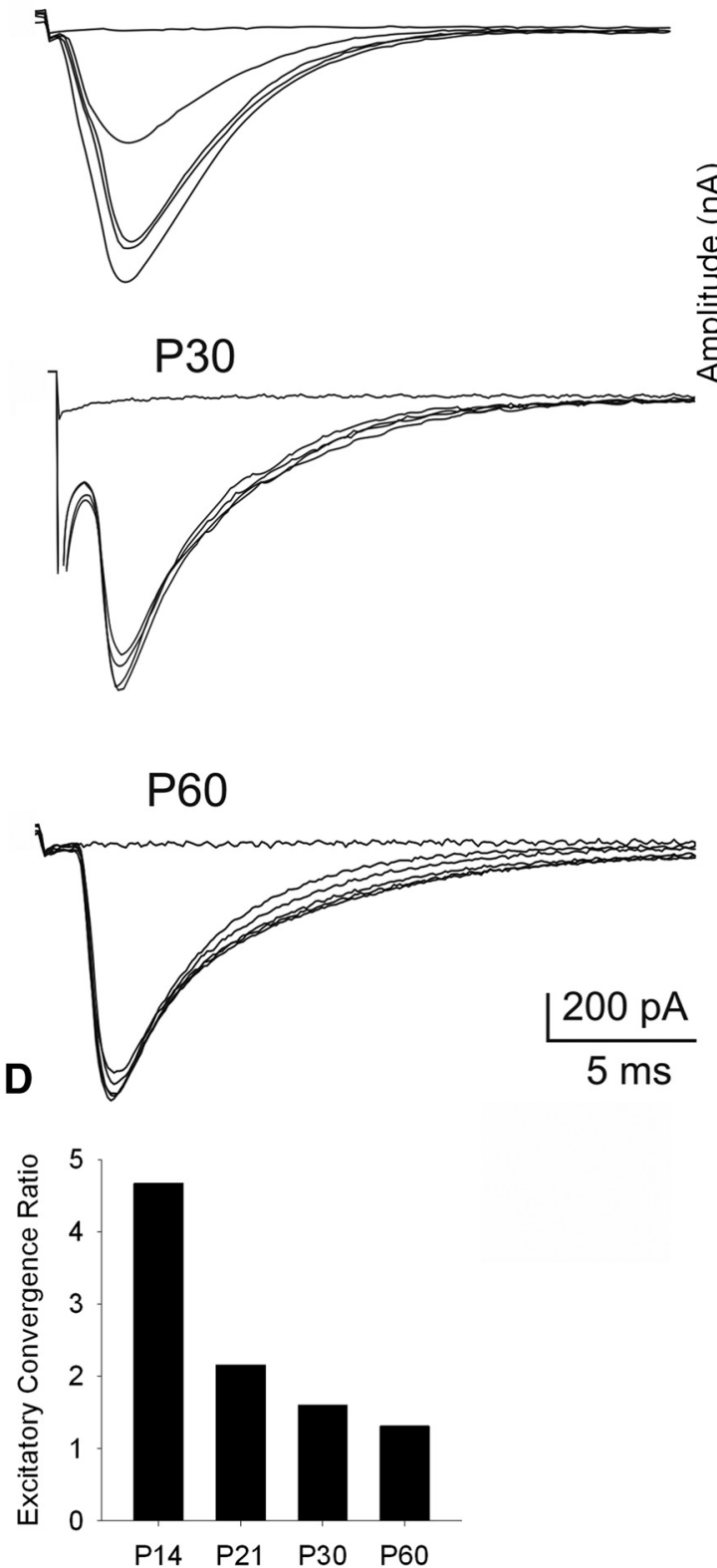

B 1.4
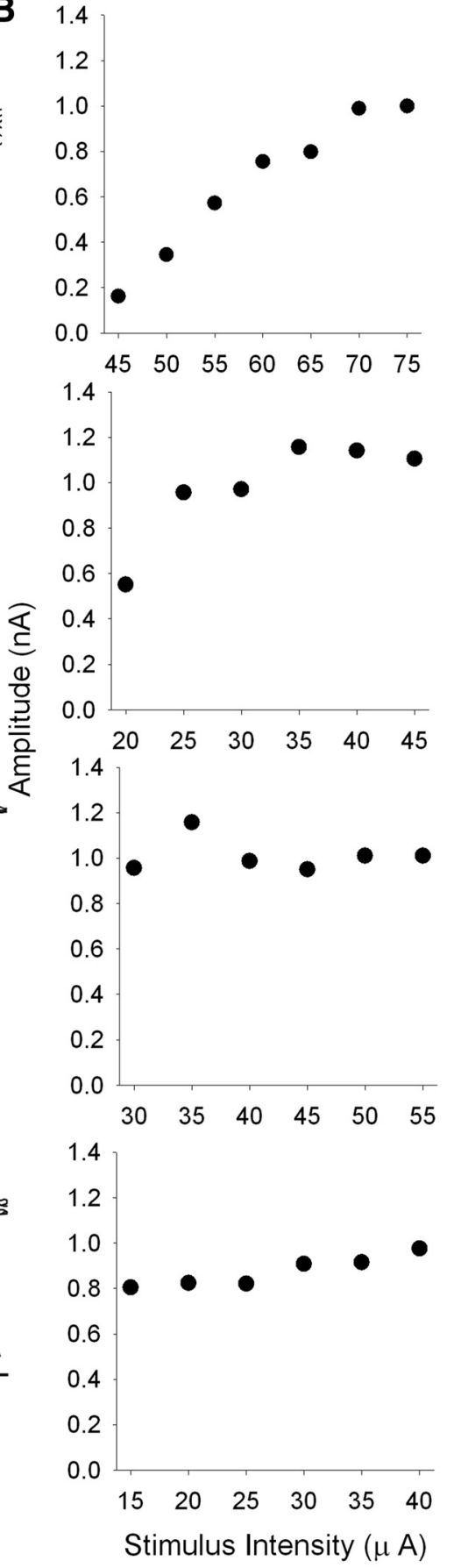

C
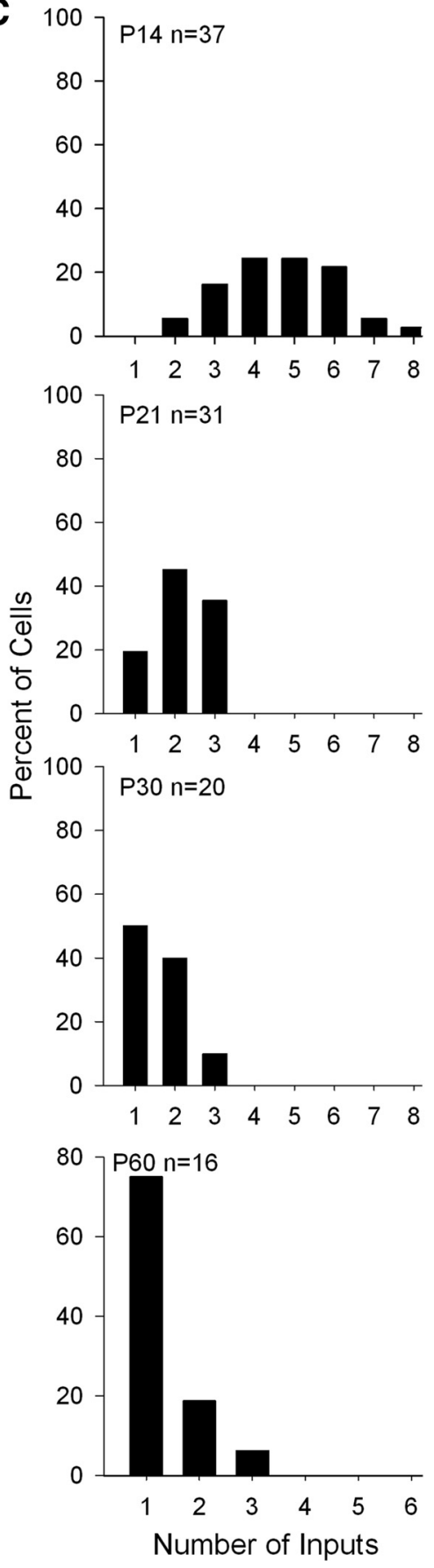

Figure 5. Patterns of excitatory retinal convergence onto dLGN neurons. $A, B$, Examples of EPSCs recorded in dLGN neurons at different postnatal ages (P14, P21, P30, P60). For each neuron, delivering a single electrical pulse to the optic tract evokes an EPSC. Successive responses are evoked by systematically increasing the stimulus intensity of optic tract stimulation. Corresponding graphs depict the amplitude by stimulus-intensity plots. Each point represents the average of five responses. Response profiles change with age, from a graded function (P14), which reflects relatively high levels of retinal convergence, to a step-like function ( $>$ P21), which depicts less convergence and few inputs. C, Frequency histograms depicting estimates of the number of retinal inputs onto single relay cells at P14, P21, P30, and P60. D. Histogram illustrating excitatory convergence ratios by age. Each bar represents the convergence ratio computed by dividing the total number of retinal inputs by the total number of cells recorded at that age. There is approximately a fourfold decrease in the number of retinal inputs between P14 and older ages. All recordings done at $-70 \mathrm{mV}$. 
and estimates of retinal convergence for individual dLGN cells were derived from their stimulus intensity by responseamplitude plots (Fig. 5B). At P14 (Fig. 5A,B), increases in stimulus intensity evoked graded increases in EPSC amplitude and a response profile that reflected a high level of convergence (Chen and Regehr, 2000; Jaubert-Miazza et al., 2005; Dilger et al., 2011, 2015). By P21, response profiles became more step-like, indicating cells received far fewer inputs. These input-output relations are summarized in Figure 5C, which plots the estimates of retinal inputs for dLGN neurons recorded at different postnatal ages. There was a significant age-related decrease in retinal convergence that occurred between P14 and P21 (Kruskal-Wallis $\mathrm{H}=$ $70.02, p<0.001$, Dunn's multiple comparisons). For example, at P14, most dLGN neurons received 4-6 inputs, but by P21 and older, dLGN neurons typically received only $1-2$ inputs. Thus, these results confirm those of the Chen laboratory (Chen and Regehr, 2000; Hooks and Chen, 2006; Litvina and Chen, 2017), as well as our previous reports (Jaubert-Miazza et al., 2005; Dilger et al., 2015). Nonetheless it should be noted, while the estimates are comparable, overall our values are lower compared with those reported by the Chen laboratory. While it is difficult to specify the reason for this, differences in the slice preparation solution, stimulation electrode configuration, and/or the threshold stimulation techniques are likely contributing factors.

To further illustrate the age-related changes in excitatory convergence, we computed a convergence ratio by dividing the total number of inputs by the total number of cells recorded at a given age (Dilger et al., 2015). As shown in 5D, when these values are plotted as a function of postnatal age, there was an $\sim 3.5$-fold decrease in the convergence ratio between P14 (4.7) and P60 (1.3). An alternative method to estimate retinal convergence is based on fiber fraction, expressed as the amplitude of the minimal single-fiber EPSC divided by the maximal EPSC, with the inverse of this fraction providing an approximation of the number of retinal inputs innervating a single dLGN neuron (Hooks and Chen 2006; Thompson et al., 2016). Consistent with the changes in convergence ratio, we found an age-related increase in fiber fraction with values that reflect a pruning of retinal inputs onto dLGN neurons (mean \pm SEM: P14, $0.10 \pm 0.06 ; \mathrm{P} 21,0.27 \pm$ 0.03; P30, $0.52 \pm 0.07$; P60, $0.69+0.07$; Kruskal-Wallis $\mathrm{H}=$ $52.3, p<0.001$, Dunn's multiple comparisons).

Accompanying the decrease in retinal convergence was an increase in the amplitude of the single-fiber response with age (mean \pm SEM: P14, $93.6 \pm 15.6$ pA; P21, $291.8 \pm 23.7$ pA; P30, $513.7 \pm 81.2 \mathrm{pA} ; \mathrm{P} 60,728.7 \pm 92.0 \mathrm{pA}$; Kruskal-Wallis $\mathrm{H}=56.2$, $p<0.001$, Dunn's multiple comparisons). However, maximal EPSC amplitude remained stable across age (mean \pm SEM: P14, $951.7 \pm 74.0$ pA; P21, $1130 \pm 90.2 \mathrm{pA} ; \mathrm{P} 30,1060.2 \pm 76.0 \mathrm{pA} ;$ $\mathrm{P} 60,1042.0 \pm 56.1 \mathrm{pA}$; Kruskal-Wallis $\mathrm{H}=3.342, p=0.34$ ).

Because retinal afferents form synapses with inhibitory interneurons, which in turn make feedforward inhibitory connections with relay neurons (Ziburkus et al., 2003; Bickford et al., 2010), we were also able to examine the degree of inhibitory convergence onto relay cells at different postnatal ages. Using cesium-based electrodes to isolate these IPSCs, and by varying the optic tract stimulus intensity, we generated stimulus-intensity plots to obtain estimates of inhibitory convergence.

Figure $6 A, B$ shows examples of the IPSCs evoked by optic tract stimulation and their corresponding stimulus intensity by amplitude plots for dLGN cells at P14, P21, and P30. In contrast to the response profiles for retinally evoked EPSCs, those for IPSCs went from a step-like to a graded fashion, thereby reflecting an age-related increase in convergence. For example IPSCs recorded at P14 (Fig. 6A,B), increases in stimulus intensity evoked a step-like increase in amplitude, whereas by P21 responses increased in a more graded fashion. These input-output relations are summarized in Figure $6 C$, which plots the estimates of inhibitory inputs for dLGN neurons recorded at different postnatal ages. There was an age-related increase in inhibitory convergence that occurred between P14 and P21 (Kruskal-Wallis $\mathrm{H}=22.1, p<0.001$, Dunn's multiple comparisons). At P14, most dLGN neurons received 1-2 inputs, but by P21 and older, dLGN neurons typically received $4-6$ inputs. Convergence ratios plotted as a function of postnatal age (Fig. $6 D$ ) reflect an $\sim 2$-fold increase between P14 and older ages. Values of fiber fraction showed a similar pattern (mean \pm SEM: P14, $0.25 \pm 0.04$; P21, $0.11 \pm 0.04 ; \mathrm{P} 30,0.11 \pm 0.07$; Kruskal-Wallis $\mathrm{H}=14, p<0.001$, Dunn's multiple comparisons). Overall, IPSCs weakened with age, with the minimum single-fiber response decreasing between P14 and older ages (mean \pm SEM: P14, $173.4 \pm 30.1 \mathrm{pA}$; $\mathrm{P} 21,89.3 \pm 38.5 \mathrm{pA}$; $\mathrm{P} 30,64.3 \pm 9.83 \mathrm{pA}$; Kruskal-Wallis $\mathrm{H}=$ $15, p<0.001$, Dunn's multiple comparisons) and maximal IPSC amplitudes decreasing from P14 to P21 and then to P30 (mean \pm SEM: P14, $778.3 \pm 65.8 \mathrm{pA} ; \mathrm{P} 21,840.3 \pm 57.0 \mathrm{pA}$; P30, $585.5 \pm 45.8$ pA; Kruskal-Wallis $\mathrm{H}=15, p<0.001$, Dunn's multiple comparisons).

\section{Discussion}

The retinogeniculate pathway of the mouse is a powerful model system to understand the mechanisms underlying the refinement of visual connections (Guido, 2008; Huberman et al., 2008; Thompson et al., 2017). However, little is known about the functional implications of such refinement. Here we link the remodeling of retinogeniculate connections with developmental changes in dLGN receptive field properties. Our in vivo recordings revealed two important changes in receptive field properties of dLGN neurons: a reduction in receptive field size and an increase in stimulus size suppression. In accord with these changes, we found a concomitant increase in the peak spatial frequency tuning. Age-matched in vitro recordings of the synaptic responses of dLGN relay neurons indicate that these changes were accompanied by a decrease in excitatory retinal convergence and an increase in feedforward inhibitory interneuron convergence.

The changes in dLGN receptive field structure likely results from the refinement of retinogeniculate connectivity, rather than protracted development of the retinal output, as our optic tract recordings show that RGC receptive field sizes undergo only a small decrease throughout the same period of development, with mean RGC receptive field size decreasing by $2^{\circ}$ while LGN receptive field size decreases by $10^{\circ}$. Together, these results suggest that the reduction in dLGN receptive field size represents the pruning of synaptic connections corresponding to inappropriate regions of visual space. We also noted that even dLGN neurons with large receptive fields are dominated by one polarity (On or Off) and one temporal type (sustained or transient). Thus, at eye opening, LGN cells receive an excessive number of excitatory RGC inputs covering an area larger than the mature receptive field but generally from the same RGC response type. This finding is consistent with reports in other mammalian species showing a general sharpening as well as reduction in receptive field size during early postnatal life (Daniels et al., 1978; Blakemore and Vital-Durand, 1986; Tavazoie and Reid, 2000), further suggesting that the period of retinogeniculate pruning is a highly conserved process confined to retinotopy rather than incorrect RGC type.

It is important to keep in mind that only a fraction of neurons responded to any given visual stimulus and had clearly defined 
A
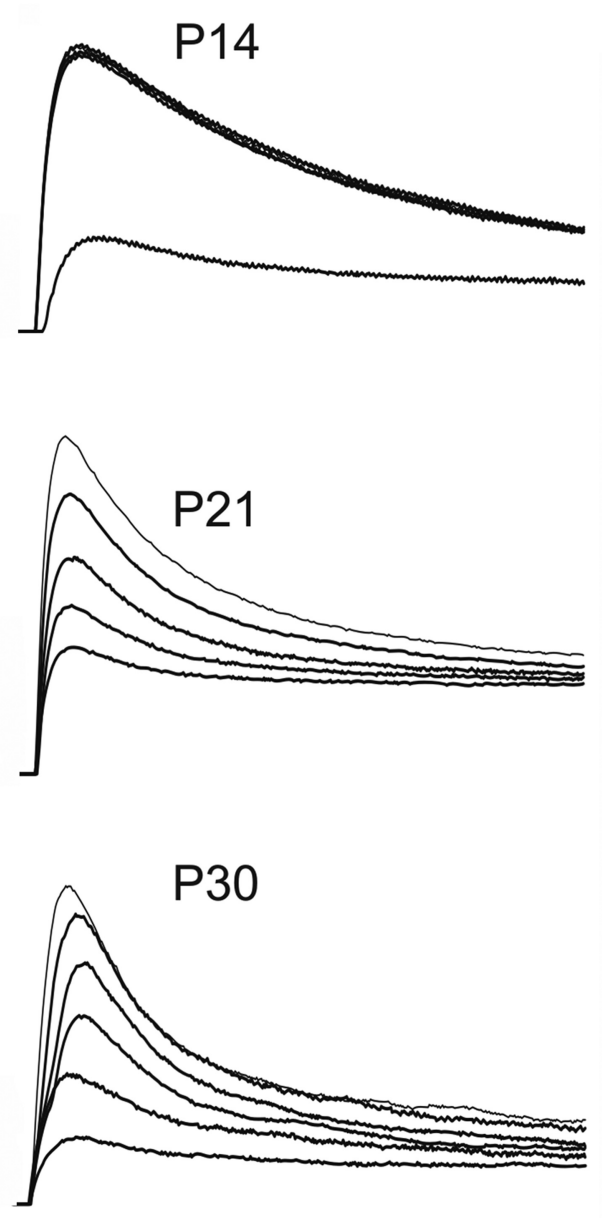

D
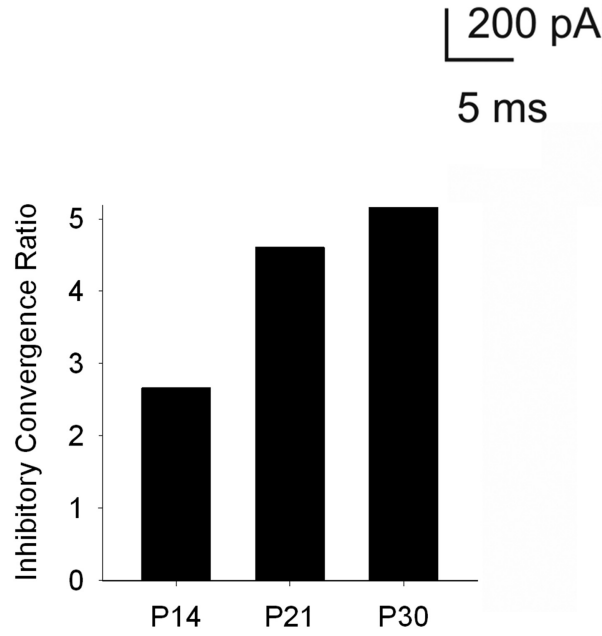

B
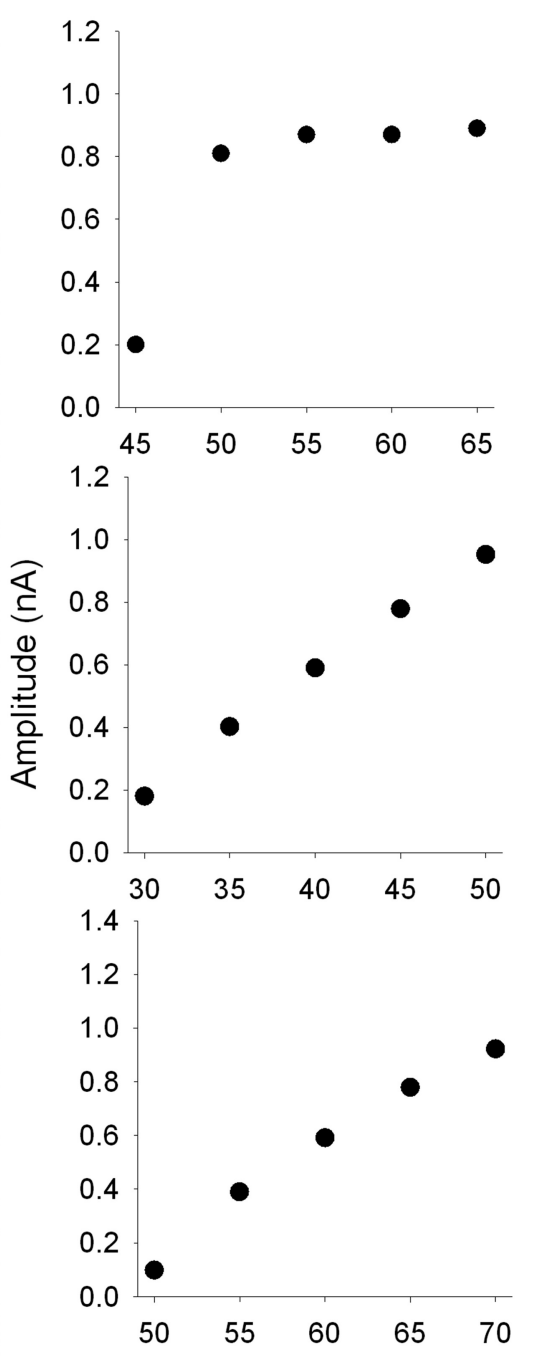

Stimulus Intensity $(\mu \mathrm{A})$
C
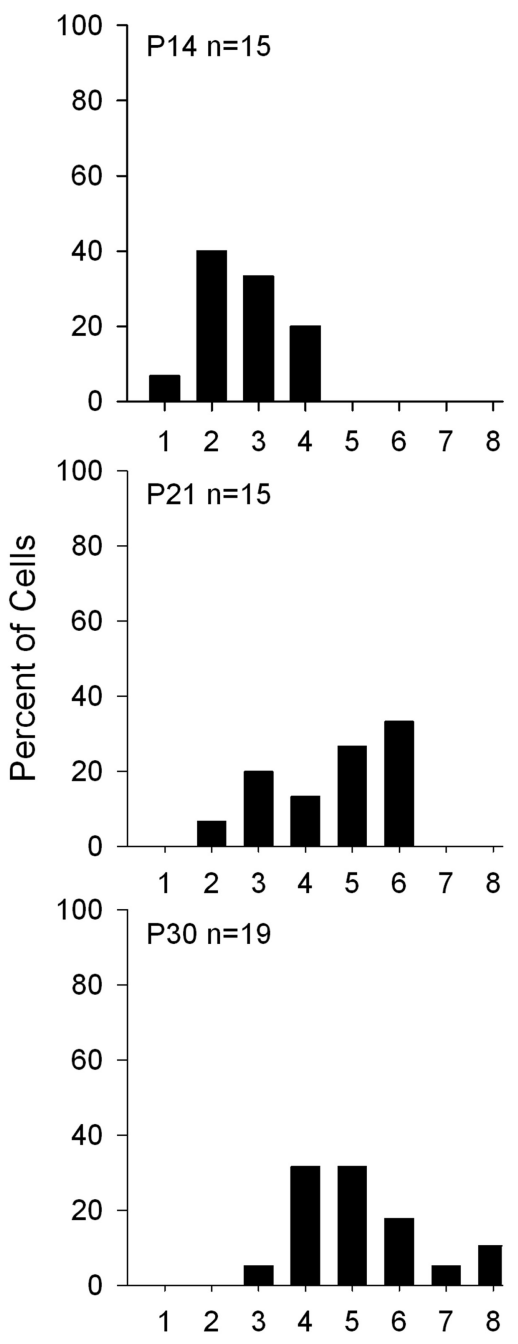

Number of Inputs

Figure 6. Patterns of feedforward inhibitory convergence onto dLGN neurons. $A, B$, Examples of IPSCs recorded in dLGN neurons at different postnatal ages (P14, P21, P30). Successive responses are evoked by systematically increasing the stimulus intensity of optic tract stimulation. Corresponding graphs depict the amplitude by stimulus-intensity plots, which are used to obtain estimates of convergence. C, Frequency histograms showing estimates for the number of inhibitory inputs onto single relay cells at P14, P21, and P30. D, Histogram illustrating feedforward inhibitory convergence ratios by age. There is approximately a twofold increase in the number of retinal inputs between P14 and older ages. All recordings done at $0 \mathrm{mV}$ using cesium-based electrodes.

spatial receptive fields. Furthermore, this fraction increased significantly over the course of development (Figs. 1B, 2A). Therefore, the neurons that were not responsive, or from which we could not map receptive fields, may be undergoing continued refinement and changes in convergence that we could not observe. However, it is apparent that once neurons have robust visual responses, their inputs are dominated by one cell type, yet can still be spatially dispersed.
Our results may seem incongruent with a recent transsynaptic labeling study suggesting that some adult dLGN relay neurons receive input from multiple, and anatomically diverse, RGC types (Rompani et al., 2017). However, it is unclear how prevalent this organization is across the population of mouse dLGNs, since at least 3 different modes of convergence were found, including a large proportion of neurons with low input convergence. Nonetheless, it should be noted that other studies 
using serial section electron microscopy also suggest that individual dLGN neurons receive far more retinal inputs than estimated using electrophysiological criteria (Hammer et al., 2015; Morgan et al., 2016). The most parsimonious explanation for this discrepancy between structure and function is that the anatomical studies uncover a large background of weak inputs that fail to provide sufficient excitatory drive to be detected using electrophysiological methods. This explanation is consistent with reports showing that the visual responses of most dLGN neurons are dominated by a single cell type (On or Off, sustained or transient, orientation selective or direction selective) with receptive field sizes similar to that of RGCs (Grubb and Thompson, 2003; Piscopo et al., 2013; Denman and Contreras, 2016; Suresh et al., 2016), suggesting that the functional output of LGN neurons is dominated by a few RGC inputs of the same type. Likewise, the possibility that many weaker inputs are present is supported by studies revealing that the visual response properties of LGN neurons can change rapidly upon removal of a subset of RGC inputs, likely representing a potentiation (or unmasking) of latent silent or weak synaptic inputs (Moore et al., 2011). Moreover, the strength and number of retinal inputs onto dLGN neurons seem quite labile and can be modified based on early visual experience. Thus, it is conceivable that only a few retinal inputs provide the excitatory drive for a dLGN neuron, while many others remain "silent," varying in synaptic strength based on age or the quality of visual experience (Chen et al., 2016; Litvina and Chen, 2017). Finally, it is important to note that regardless of the absolute number of inputs converging onto an LGN cell, our quantification provides a consistent estimate (albeit conservative), and that the potential factors influencing the ability to detect weak ones remains the same across cells and age.

While the pruning of excitatory retinal inputs onto dLGN neurons has been well established (Guido, 2008; Hong and Chen, 2011), this study is the first demonstration that concurrent with a decrease in excitatory retinal convergence, inhibitory convergence via feedforward connections between interneurons and relay neurons increases with age. It is important to note that the increase in feedforward inhibitory convergence cannot be attributed to any changes in the functional properties of interneurons. Their input resistance, resting membrane levels, and spike-firing properties remain stable after the first postnatal week (Seabrook et al., 2013). Moreover, unlike relay neurons, interneurons do not undergo retinal pruning, but instead maintain a high degree of retinal convergence that is relatively constant (Seabrook et al., 2013).

The age-related increase in inhibitory convergence could certainly contribute to the observed reduction in receptive field size (Wang et al., 2011; Hirsch et al., 2015). Additionally, such an increase is likely to underlie our in vivo results showing an agerelated increase in size suppression. In mature LGN neurons, we found response to a full-field flash was much less than the response to a spot of the optimal size, suggesting an increase in the center-surround receptive field organization of dLGN neurons with age. Indeed, similar to neurons in other mammalian species, many neurons in mouse dLGNs display a center surround that is mediated by a push-pull model of synaptic excitation and inhibition (Suresh et al., 2016).

The differences in anatomical organization of the LGN across species have been well characterized, including in mouse, cat, ferret, and monkey. Despite these differences, the development of mature receptive fields of individual neurons appears to be much the same. It has been shown in cats (Daniels et al., 1978) and monkeys (Blakemore and Vital-Durand, 1986) that LGN recep- tive field size decreases during postnatal development. Tavazoie and Reid (2000) found LGN receptive fields in ferrets that were both larger and more diverse in shape during development than in the adult. These results could be accounted for by topographical elimination of inputs, which would also result in a more homogenous receptive field structure in adulthood.

Our experiments have confirmed and extended these findings in mice in two ways. First, our data link the in vitro measurements of retinogeniculate synaptic connectivity in mouse with in vivo recordings of LGN receptive fields, which are the functional output of the retinogeniculate circuit, in the same species across the same age range. Second, our results show that only certain aspects of the LGN receptive field are modified during this pruning receptive field size decreases, but the degree of On/Off and sustained/transient specificity are already refined before eye opening. Together, the data support a model where the decrease in size of receptive fields is due to selective elimination of excitatory inputs from a functionally homogenous, but retinotopically diverse, pool of RGCs. Coupled with this is an expansion of feedforward inhibitory drive that most likely mediates increased surround suppression. These findings should thus provide a basis for testing the cell-type-specific plasticity mechanisms that lead to refinement of different excitatory and inhibitory inputs, and for determining the effect of these mechanisms on the establishment of mature receptive fields in the LGN.

\section{References}

Bickford ME, Slusarczyk A, Dilger EK, Krahe TE, Kucuk C, Guido W (2010) Synaptic development of the mouse dorsal lateral geniculate nucleus. J Comp Neurol 518:622-635. CrossRef Medline

Blakemore C, Vital-Durand F (1986) Organization and post-natal development of the monkey's lateral geniculate nucleus. J Physiol 380:453-491. CrossRef Medline

Brainard DH (1997) The psychophysics toolbox. Spat Vis 10:433-436. CrossRef Medline

Cantrell DR, Cang J, Troy JB, Liu X (2010) Noncentered spike-triggered covariance analysis reveals neurotrophin-3 as a developmental regulator of receptive field properties of ON-OFF retinal ganglion cells. PLoS Comput Biol 6:e1000967. CrossRef Medline

Chen C, Regehr WG (2000) Developmental remodeling of the retinogeniculate synapse. Neuron 28:955-966. CrossRef Medline

Chen C, Bickford ME, Hirsch JA (2016) Untangling the web between eye and brain. Cell 165:20-21. CrossRef Medline

Crandall SR, Cox CL (2013) Thalamic microcircuits: presynaptic dendrites form two inhibitory pathways in thalamus. J Neurophysiol 110:470-480. CrossRef Medline

Daniels JD, Pettigrew JD, Norman JL (1978) Development of single-neuron responses in kitten's lateral geniculate nucleus. J Neurophysiol 41:13731393. CrossRef Medline

Denman DJ, Contreras D (2016) On parallel streams through the mouse dorsal lateral geniculate nucleus. Front Neural Circuits 10:20. CrossRef Medline

Dilger EK, Shin HS, Guido W (2011) Requirements for synaptically evoked plateau potentials in relay cells of the dorsal lateral geniculate nucleus of the mouse. J Physiol 589:919-937. CrossRef Medline

Dilger EK, Krahe TE, Morhardt DR, Seabrook TA, Shin HS, Guido W (2015) Absence of plateau potentials in dLGN cells leads to a breakdown in retinogeniculate refinement. J Neurosci 35:3652-3662. CrossRef Medline

Dombeck DA, Khabbaz AN, Collman F, Adelman TL, Tank DW (2007) Imaging large-scale neural activity with cellular resolution in awake, mobile mice. Neuron 56:43-57. CrossRef Medline

Grubb MS, Thompson ID (2003) Quantitative characterization of visual response properties in the mouse dorsal lateral geniculate nucleus. J Neurophysiol 90:3594-3607. CrossRef Medline

Guido W (2008) Refinement of the retinogeniculate pathway. J Physiol 586: 4357-4362. CrossRef Medline

Hammer S, Monavarfeshani A, Lemon T, Su J, Fox MA (2015) Multiple retinal axons converge onto relay cells in the adult mouse thalamus. Cell Rep 12:1575-1583. CrossRef Medline 
Harris KD, Henze DA, Csicsvari J, Hirase H, Buzsáki G (2000) Accuracy of tetrode spike separation as determined by simultaneous intracellular and extracellular measurements. J Neurophysiol 84:401-414. CrossRef Medline

Hirsch JA, Wang X, Sommer FT, Martinez LM (2015) How inhibitory circuits in the thalamus serve vision. Annu Rev Neurosci 38:309-329. CrossRef Medline

Hong YK, Chen C (2011) Wiring and rewiring of the retinogeniculate synapse. Curr Opin Neurobiol 21:228-237. CrossRef Medline

Hooks BM, Chen C (2006) Distinct roles for spontaneous and visual activity in remodeling of the retinogeniculate synapse. Neuron 52:281-291. CrossRef Medline

Huberman AD, Feller MB, Chapman B (2008) Mechanisms underlying development of visual maps and receptive fields. Annu Rev Neurosci 31: 479-509. CrossRef Medline

Jaubert-Miazza L, Green E, Lo FS, Bui K, Mills J, Guido W (2005) Structural and functional composition of the developing retinogeniculate pathway in the mouse. Vis Neurosci 22:661-676. CrossRef Medline

Koehler CL, Akimov NP, Rentería RC (2011) Receptive field center size decreases and firing properties mature in $\mathrm{ON}$ and OFF retinal ganglion cells after eye opening in the mouse. J Neurophysiol 106:895-904. CrossRef Medline

Krahe TE, El-Danaf RN, Dilger EK, Henderson SC, Guido W (2011) Morphologically distinct classes of relay cells exhibit regional preferences in the dorsal lateral geniculate nucleus of the mouse. J Neurosci 31:1743717448. CrossRef Medline

Levick WR, Cleland BG, Dubin MW (1972) Lateral geniculate neurons of cat: retinal inputs and physiology. Invest Ophthalmol 11:302-311. Medline

Litvina EY, Chen C (2017) Functional convergence at the retinogeniculate synapse. Neuron 96:330-338.e5. CrossRef Medline

Marshel JH, Kaye AP, Nauhaus I, Callaway EM (2012) Anterior-posterior direction opponency in the superficial mouse lateral geniculate nucleus. Neuron 76:713-720. CrossRef Medline

Mastronarde DN (1987) Two classes of single-input X-cells in cat lateral geniculate nucleus. II. Retinal inputs and the generation of receptive-field properties. J Neurophysiol 57:381-413. CrossRef Medline

Moore BD 4th, Kiley CW, Sun C, Usrey WM (2011) Rapid plasticity of visual responses in the adult lateral geniculate nucleus. Neuron 71:812819. CrossRef Medline

Morgan JL, Berger DR, Wetzel AW, Lichtman JW (2016) The fuzzy logic of network connectivity in mouse visual thalamus. Cell 165:192-206. CrossRef Medline

Niell CM, Stryker MP (2008) Highly selective receptive fields in mouse visual cortex. J Neurosci 28:7520-7536. CrossRef Medline

Niell CM, Stryker MP (2010) Modulation of visual responses by behavioral state in mouse visual cortex. Neuron 65:472-479. CrossRef Medline
Pelli DG (1997) The VideoToolbox software for visual psychophysics: transforming numbers into movies. Spat Vis 10:437-442. CrossRef Medline

Piscopo DM, El-Danaf RN, Huberman AD, Niell CM (2013) Diverse visual features encoded in mouse lateral geniculate nucleus. J Neurosci 33:46424656. CrossRef Medline

Rompani SB, Müllner FE, Wanner A, Zhang C, Roth CN, Yonehara K, Roska B (2017) Different modes of visual integration in the lateral geniculate nucleus revealed by single-cell-initiated transsynaptic tracing. Neuron 93:767-776.e6. CrossRef Medline

Sagdullaev BT, McCall MA (2005) Stimulus size and intensity alter fundamental receptive-field properties of mouse retinal ganglion cells in vivo. Vis Neurosci 22:649-659. CrossRef Medline

Seabrook TA, Krahe TE, Govindaiah G, Guido W (2013) Interneurons in the mouse visual thalamus maintain a high degree of retinal convergence throughout postnatal development. Neural Dev 8:24. CrossRef Medline

Sharpee T, Rust NC, Bialek W (2004) Analyzing neural responses to natural signals: maximally informative dimensions. Neural Comput 16:223-250. CrossRef Medline

Suresh V, Çiftçioğlu UM, Wang X, Lala BM, Ding KR, Smith WA, Sommer FT, Hirsch JA (2016) Synaptic contributions to receptive field structure and response properties in the rodent lateral geniculate nucleus of the thalamus. J Neurosci 36:10949-10963. CrossRef Medline

Tavazoie SF, Reid RC (2000) Diverse receptive fields in the lateral geniculate nucleus during thalamocortical development. Nat Neurosci 3:608-616. CrossRef Medline

Thompson AD, Picard N, Min L, Fagiolini M, Chen C (2016) Cortical feedback regulates feedforward retinogeniculate refinement. Neuron 91: 1021-1033. CrossRef Medline

Thompson A, Gribizis A, Chen C, Crair MC (2017) Activity-dependent development of visual receptive fields. Curr Opin Neurobiol 42:136-143. CrossRef Medline

Tian N, Copenhagen DR (2003) Visual stimulation is required for refinement of ON and OFF pathways in postnatal retina. Neuron 39:85-96. CrossRef Medline

Usrey WM, Reppas JB, Reid RC (1999) Specificity and strength of retinogeniculate connections. J Neurophysiol 82:3527-3540. CrossRef Medline

Wang X, Sommer FT, Hirsch JA (2011) Inhibitory circuits for visual processing in thalamus. Curr Opin Neurobiol 21:726-733. CrossRef Medline

Wolfe J, Palmer LA (1998) Temporal diversity in the lateral geniculate nucleus of cat. Vis Neurosci 15:653-675. Medline

Zhao X, Chen H, Liu X, Cang J (2013) Orientation-selective responses in the mouse lateral geniculate nucleus. J Neurosci 33:12751-12763. CrossRef Medline

Ziburkus J, Lo FS, Guido W (2003) Nature of inhibitory postsynaptic activity in developing relay cells of the lateral geniculate nucleus. J Neurophysiol 90:1063-1070. CrossRef Medline 